\title{
Chemical Synthesis and Some Properties of 6-Substituted Flavins ${ }^{\dagger}$
}

\author{
Sandro Ghisla, William C. Kenney, Wolfgang R. Knappe, William McIntire, and Thomas P. Singer*
}

ABSTRACT: A number of derivatives of riboflavin and of 3methyllumiflavin substituted in the 6 position have been synthesized starting with 6-nitro flavins, reduction to the 6amino flavin, and diazotization, followed by reaction with the appropriate nucleophile. The absorption spectra, oxidationreduction potentials, and the electron spin resonance spectra of the radical cationic forms of several of these synthetic compounds have been determined, including 6-S-cysteinyl-3methyllumiflavin and 6-S-cysteinylriboflavin. The latter has been shown to be identical with the dephosphorylated form

$\mathbf{U}$ ntil about 1976 all covalently bound flavins were thought to be attached to proteins via the $8 \alpha$ position (Edmondson $\&$ Singer, 1976). Recently, however, evidence was presented to show that in bacterial trimethylamine dehydrogenase the flavin is linked to the protein by a thioether bridge between a cysteine residue and $\mathrm{C}(6)$ of the isoalloxazine nucleus (Steenkamp et al., 1978a,b). The natural occurrence of flavin nucleotides substituted in the 6 position has also been reported by Mayhew et al. (1974). These authors reported that pig liver glycolate oxidase contains 6-OH-FMN and that the electron-transferring flavoprotein from Peptostreptococcus elsdenii contains, besides FAD and 8-OH-FAD, 6-OH-FAD, although the flavins in these instances are noncovalently attached to the protein. Collectively, these data point to the importance of 6-substituted flavins in biological systems and suggest the need to elaborate methods for their chemical synthesis and characterization.

The present paper describes the synthesis and properties of several derivatives of riboflavin and of 3-methyllumiflavin

\footnotetext{
${ }^{\dagger}$ From the Fakultät für Biologie, University of Konstanz, Postfach 5560, D-7750, Konstanz, West Germany (S.G. and W.R.K.), the Liver Studies Unit (W.C.K.) and the Molecular Biology Division (W.M. and T.P.S.), Veterans Administration Medical Center, San Francisco, California 94121, and the Departments of Medicine (W.C.K.) and of Biochemistry and Biophysics (T.P.S.), University of California, San Francisco, California 94143. Received January 21, 1980. This investigation was supported by grants from the Deutsche Forschungsgemeinschaft (Gh $2 / 3$ ) to the Konstanz laboratory and from the National Institutes of Health (HL 16251) and the National Science Foundation (PCM 7681453 ) to the San Francisco laboratories and by the Veterans Administration.

* Correspondence should be addressed to this author at the Molecular Biology Division, Veterans Administration Medical Center, San Francisco, CA 94121
}

of the aminoacyl flavin isolated from trimethylamine dehydrogenase [Steenkamp, D. J., Kenney, W. C., \& Singer, T. P. (1978) J. Biol. Chem. 253, 2812-2817; Steenkamp, D. J., McIntire, W., \& Kenney, W. C. (1978) J. Biol. Chem. 253, 2818-2824] in regard to absorption spectrum, photochemical properties, and mobility in high-voltage electrophoresis and in thin-layer chromatography. An unusually pronounced interaction between the amino group and the isoalloxazine ring system was deduced from the absorption spectra of 6-amino3-methyllumiflavin and 6-aminoriboflavin.

substituted at $C(6)$, including 6-S-cysteinylriboflavin thioether. The latter compound is shown to be identical with the dephosphorylation product of the aminoacyl flavin isolated from trimethylamine dehydrogenase, providing further, conclusive evidence for the previously proposed structure of the covalently bound flavin prosthetic group of that enzyme.

\section{Experimental Section}

\section{Materials}

Trimethylamine dehydrogenase (EC 1.5.99.7) was purified to homogeneity as previously described (Steenkamp \& Mallinson, 1976). Preparation of the aminoacyl flavin of this enzyme and derivatives thereof has been documented (Steenkamp et al., 1978a,b). Riboflavin-binding protein from chicken egg white was obtained by the method of Blankenhorn et al. (1975). Thin-layer chromatography was performed with Merck precoated plates.

\section{Methods}

6-Amino-3-methyllumiflavin (1). To an aqueous suspension of $2.0 \mathrm{~g}(6.35 \mathrm{mmol})$ of 3-methyl-6-nitrolumiflavin (Knappe, 1979), $12.0 \mathrm{~g}$ of sodium dithionite in $40 \mathrm{~mL}$ of $10 \%$ ammonia was added, resulting in the formation of a black precipitate. After this solid was heated to $90^{\circ} \mathrm{C}$, it dissolved, the solution turned yellow, and light yellow crystals began to form. After 5 min at $100^{\circ} \mathrm{C}$, the solution was cooled to and kept at $0^{\circ} \mathrm{C}$ for $1 \mathrm{~h}$. The solid was filtered off and washed with water, dilute acetic acid, and methanol. The crystals of 6-amino1,5-dihydro-3-methyllumiflavin turned dark brown on exposure to oxygen. The yield of 1 was $400 \mathrm{mg}(88 \%)$. Anal. Calcd for $\mathrm{C}_{14} \mathrm{H}_{15} \mathrm{~N}_{5} \mathrm{O}_{2} \cdot \mathrm{H}_{2} \mathrm{O}: C, 55.43 ; \mathrm{H}, 5.65 ; \mathrm{N}, 23.09$. Found: $\mathrm{C}, 55.87 ; \mathrm{H}, 5.81 ; \mathrm{N}, 23.23 . \mathrm{MS}^{1}\left(70 \mathrm{eV}, 225^{\circ} \mathrm{C}\right) \mathrm{m} / \mathrm{z}(\mathrm{rel}$ 
intensity) $285\left(\mathrm{M}^{+}, 21\right), 284\left(\mathrm{M}^{+}-\mathrm{H}, 100\right), 227\left(\mathrm{M}^{+}-\mathrm{H}\right.$ $\left.-\mathrm{CH}_{3} \mathrm{NCO}, 53\right)$.

6-Aminoriboflavin (2). This compound was obtained by the reduction of $2^{\prime}, 3^{\prime}, 4^{\prime}, 5^{\prime}$-tetraacetyl-6-nitroriboflavin (Litvak \& Berezovskii, 1978; Knappe, 1979) with dithionite in the presence of ammonia analogously to the reduction of 3methyl-6-nitrolumiflavin. Under these conditions the acetyl groups are hydrolyzed. The yield of 2 was $74 \%$. ' $\mathrm{H}$ NMR (in $\left.\mathrm{CF}_{3} \mathrm{CO}_{2} \mathrm{H}\right) \delta 2.49\left(\mathrm{~s}, 3 \mathrm{H}, 7-\mathrm{CH}_{3}\right), 2.80\left(\mathrm{~s}, 3 \mathrm{H}, 8-\mathrm{CH}_{3}\right)$, 4.06-5.35 $\left(\mathrm{m}, 8 \mathrm{H}\right.$, side chain protons and $\left.\mathrm{NH}_{2}\right), 7.68(\mathrm{~s}, 1$ $\mathrm{H}$, 9-H).

$2^{\prime}, 3^{\prime}, 4^{\prime}, 5^{\prime}$-Tetraacetyl-6-aminoriboflavin. This was synthesized the same way as 2 but at $\mathrm{pH} 10.5$, in sodium carbonate buffer, in the absence of ammonia. The yield was $78 \%$. ${ }^{1} \mathrm{H}$ NMR $\left(\mathrm{CF}_{3} \mathrm{CO}_{2} \mathrm{H}\right) \delta 1.96,2.20,2.31,2.57$, and $2.80(5$ $\mathrm{s}, 6 \mathrm{CH}_{3}$ groups), $4.25-6.10(\mathrm{~m}, 8 \mathrm{H}$, corresponding to ribityl side-chain protons and $\left.\mathrm{NH}_{2}\right), 7.82(\mathrm{~s}, 9-\mathrm{H})$.

6-Bromo-3-methyllumiflavin (3). Five hundred milligrams of 1 was dissolved in $5 \mathrm{~mL}$ of concentrated $\mathrm{H}_{2} \mathrm{SO}_{4}$ and poured on $25 \mathrm{~g}$ of ice. Sodium nitrite ( $175 \mathrm{mg}$; $50 \%$ excess) was added slowly at $0^{\circ} \mathrm{C}$, resulting in a color change from red brown to golden orange. The solution was stirred for $15 \mathrm{~min}$; then $180 \mathrm{mg}$ of urea was added slowly to destroy excess nitrite and, after further 15 -min stirring, saturated with potassium bromide. After the solution was stirred at room temperature overnight, the $\mathrm{pH}$ was adjusted to between 5 and 8; the orange precipitate was filtered off and washed with water and ethanol: yield, $270 \mathrm{mg}(52 \%)$. MS $\left(70 \mathrm{eV}, 300^{\circ} \mathrm{C}\right) \mathrm{m} / \mathrm{z}$ (rel intensity) $350\left(\mathrm{M}^{+}+2,100\right), 348\left(\mathrm{M}^{+}, 95\right), 293\left(\mathrm{M}^{+}+2-\mathrm{CH}_{3} \mathrm{NCO}\right.$, 69), $291\left(\mathrm{M}^{+}-\mathrm{CH}_{3} \mathrm{NCO}, 66\right)$.

6-Bromoriboflavin (4). This was obtained by the same procedure as 3 from compound $\mathbf{2}$ in $40 \%$ yield. Anal. Calcd for $\mathrm{C}_{17} \mathrm{H}_{19} \mathrm{BrN}_{4} \mathrm{O}_{6}: \mathrm{C}, 44.9 ; \mathrm{H}, 4.21 ; \mathrm{N}, 12.3 ; \mathrm{Br}, 17.5$. Found: $\mathrm{C}, 45.1 ; \mathrm{H}, 4.15 ; \mathrm{N}, 12.3 ; \mathrm{Br}, 16.5$. Absorption spectrum: $\lambda_{\max }$ $=445(\epsilon \sim 9700)$ and $397 \mathrm{~nm}(\epsilon \sim 12500) .{ }^{1} \mathrm{H}$ NMR $\left(\mathrm{CF}_{3} \mathrm{CO}_{2} \mathrm{H}\right) \delta 2.80\left(\mathrm{~s}, 3 \mathrm{H}, 7-\mathrm{CH}_{3}\right), 2.84\left(\mathrm{~s}, 3 \mathrm{H}, 8-\mathrm{CH}_{3}\right)$, $4.05-5.85(\mathrm{~m}, 7 \mathrm{H}$, ribityl side-chain protons $), 8.12(\mathrm{~s}, 1 \mathrm{H}$, 9-H).

6-(Thiocyanato)-3-methyllumiflavin (5). Compound 1 (300 $\mathrm{mg}, 1.05 \mathrm{mmol}$ ) was dissolved in $1.5 \mathrm{~mL}$ of concentrated $\mathrm{H}_{2} \mathrm{SO}_{4} ; 4.5 \mathrm{~g}$ of ice was added and diazotization was carried out as described above for 3 . Saturated KSCN solution $(0.5$ $\mathrm{mL}$ ) was then added slowly and the solution was kept at $0{ }^{\circ} \mathrm{C}$ until nitrogen evolution ceased. The $\mathrm{pH}$ of the solution was then adjusted to 2 with concentrated ammonium hydroxide, and the crystalline product was filtered, thoroughly washed with water and a little methanol, and dried in vacuo: yield, $250 \mathrm{mg}$. The product contained only a trace of 3-methyllumiflavin by thin-layer chromatography (silica plates; 1 -butanol-acetic acid-water, 6:2:2 v/v/v). MS $\left(70 \mathrm{eV}, 250^{\circ} \mathrm{C}\right)$ $\mathrm{m} / \mathrm{z}$ (rel intensity) $327\left(\mathrm{M}^{+}, 26\right), 313(30), 270\left(\mathrm{M}^{+}-\right.$ $\left.\mathrm{CH}_{3} \mathrm{NCO}, 100\right)$; IR $(\mathrm{KBr}) 2160(\mathrm{C} \equiv \mathrm{N}), 1700[\mathrm{C}(4)=\mathrm{O}]$, $1660 \mathrm{~cm}^{-1}[\mathrm{C}(2)=0]$.

The corresponding 6-(thiocyanato)riboflavin was synthesized analogously, but the product could not be crystallized and was thus used without further purification.

6-(Ethylxanthyl)-3-methyllumiflavin. This compound was prepared from 6 -amino-3-methyllumiflavin $(110 \mathrm{mg}, \sim 0.4$ $\mathrm{mmol}$ ) by reaction of the diazotate (cf. above) with potassium ethylxanthate ( $96 \mathrm{mg}, 0.6 \mathrm{mmol}$ ) dissolved in $1 \mathrm{~mL}$ of water at $0{ }^{\circ} \mathrm{C}$. The reaction mixture was brought to ambient tem-

\footnotetext{
' Abbreviations used: NMR, nuclear magnetic resonance; EPR, electron paramagnetic resonance; MS, mass spectrum; IR, infrared spectrum.
}

perature for $20 \mathrm{~min}$ and then warmed at $60^{\circ} \mathrm{C}$ for $5 \mathrm{~min}$. The precipitate was filtered, washed with water, and recrystallized from ethanol to yield $60 \mathrm{mg}$ of the product. This compound showed on thin-layer chromatography (silica plates; 1-butanol-acetic acid-water, 6:2:2 v/v/v) a major nonfluorescent spot corresponding to the 6-ethylxanthate derivative and a minor fluorescent spot corresponding to 3-methyllumiflavin.

Hydrolysis of this product yields as a main product 6thio-3-methyllumiflavin. For hydrolysis, $20 \mathrm{mg}$ of the 6xanthate derivative was refluxed in $2 \mathrm{~mL}$ of $6 \mathrm{~N} \mathrm{HCl}$ for 6 $h$, the solvent was evaporated in vacuo, and the residue was dissolved in a minimum volume of warm glacial acetic acid. Upon addition of water and cooling, a precipitate was obtained which was filtered and washed with water. This material was free of 3-methyllumiflavin, consisted of a mixture of 3methyl-6-thiolumiflavin and its oxidation product, the 6-SSdimer, and, according to thin-layer chromatography (silica plates; 1-butanol-acetic acid-water, 6:2:2 v/v/v), was identical with the products obtained as described below.

6-Thio-3-methyllumiflavin. Fifty milligrams of 5 was suspended in $2 \mathrm{~mL}$ of water under a stream of nitrogen, solid sodium dithionite was then added until the color of the suspension turned yellow, and a precipitate of reduced 6-thio-3methyllumiflavin was formed. During the procedure the $\mathrm{pH}$ of the solution was held at 8-9 with dilute ammonia. The precipitate was then filtered and washed with water and a little methanol. The reduced compound was rapidly reoxidized by air. When a suspension is stirred in aqueous solution at $\mathrm{pH}$ at $6-7$, the green color of the 6-S compound is rapidly formed, which then turns to yellow orange due to formation of the dimer (6-SS-).

6-S-Cysteinyl-3-methyllumiflavin. Ten micromoles of 3 was dissolved in $16 \mathrm{~mL}$ of dimethylformamide and $144 \mathrm{~mL}$ of 0.1 $\mathrm{M} \mathrm{Na}_{2} \mathrm{CO}_{3}, \mathrm{pH} 10.9$. To this $16 \mathrm{~mL}$ of freshly prepared 0.5 $\mathrm{M}$ cysteine hydrochloride, adjusted to $\mathrm{pH} 9.0$, was added. Following incubation for $22 \mathrm{~h}$ at ambient temperature, the $\mathrm{pH}$ of the reaction mixture was adjusted to 7.0 and the solution was extracted 3 times with an equal volume of $\mathrm{CHCl}_{3}$ to remove any unreacted starting material. To the aqueous phase 0.1 volume of $55 \%(\mathrm{w} / \mathrm{v})$ trichloroacetic acid was added, and reduced pressure was applied to remove $\mathrm{CO}_{2}$. The solution was then applied to a column of Florisil $(0.9 \times 6 \mathrm{~cm})$ equilibrated with $5 \%(\mathrm{v} / \mathrm{v})$ acetic acid. The column was washed with $5 \%$ acetic acid and water, and then the flavin was eluted with $20 \%(\mathrm{v} / \mathrm{v})$ pyridine. The eluate was directly applied to a column $(0.9 \times 5 \mathrm{~cm})$ of DEAE-cellulose (acetate form), equilibrated with $20 \%$ pyridine. 6-S-Cysteinyl-3-methyllumiflavin came off the column in $20 \%$ pyridine, while some green-colored material (presumably 6- $N$-cysteinyl-3-methyllumiflavin) was retained on the column. The yield of $6-5$ cysteinyl-3-methyllumiflavin was $55 \%$.

6-S-Cysteinylriboflavin. Five micromoles $(2.3 \mathrm{mg})$ of $6-$ bromoriboflavin was dissolved in $6 \mathrm{~mL}$ of dimethylformamide, and this was diluted with $50 \mathrm{~mL}$ of $0.1 \mathrm{M}$ sodium carbonate, $\mathrm{pH}$ 11. A freshly prepared solution of $486 \mathrm{mg}$ of cysteine ( 4 $\mathrm{mmol}$ ) in $8 \mathrm{~mL}$ of water ( $\mathrm{pH}$ adjusted to $\sim 9$ ) was added ( $\mathrm{pH}$ of mixture $\sim 10$ ) and then stirred at $22^{\circ} \mathrm{C}$ for $22 \mathrm{~h}$ in the dark. The $\mathrm{pH}$ of the solution was then adjusted to 7 with acetic acid, the precipitate which formed was filtered off, and the filtrate was evaporated in vacuo to a volume of $\sim 20 \mathrm{~mL}$. A $10-\mathrm{mL}$ aliquot was applied to a Florisil column $(1 \times 10 \mathrm{~cm})$, equilibrated with $5 \%$ acetic acid. The column was washed with $5 \%$ acetic acid and then water, and the total flavin was eluted with $20 \%$ pyridine. The eluate was evaporated to dryness in vacuo; the residue was dissolved in $0.1 \mathrm{M}$ potassium phosphate 
buffer, $\mathrm{pH} 7.0$, and then applied to an affinity column consisting of riboflavin-binding protein immobilized to Sepharose B [riboflavin-binding capacity was $1.5 \mu \mathrm{mol}$ [prepared by the method of Mayhew \& Strating (1975)]]. Riboflavin derivatives which do not carry a charged function are bound by this column, while $6-S$-cysteinylriboflavin is not retained. The compound was obtained with a yield of $35-40 \%$ and is pure by chromatographic (silica plates; 1-butanol-acetic acid-water, 6:2:2 and $4: 3: 2 \mathrm{v} / \mathrm{v} / \mathrm{v}$ ) and spectroscopic criteria. Upon aging, small quantities of the rearrangement product, $6-N$-cysteinylriboflavin, may form, which can be separated by DEAE chromatography as described above for 6-S-cysteinyl-3methyllumiflavin.

6-(N-Acetylamino)-3-methyllumiflavin. Acetylation of 6-amino-3-methyllumiflavin ( $30 \mathrm{mg}$ ) was achieved by gently heating in $1 \mathrm{~mL}$ of acetic anhydride-acetic acid $(2: 1 \mathrm{v} / \mathrm{v})$ and 1 drop of trifluoroacetic acid until the dark brown solid was dissolved and a clear yellow solution was formed. The solvent was evaporated to dryness in vacuo, and the yellow residue was recrystallized from the minimal amount of acetic acidwater to yield $25 \mathrm{mg}$ of the pure acetylated compound. ${ }^{1} \mathrm{H}$ NMR $\left(\mathrm{D}_{2} \mathrm{O}\right) \delta 2.30\left(6 \mathrm{H}, 7\right.$ - and $\left.8-\mathrm{CH}_{3}\right), 2.68(\mathrm{~s}, 3 \mathrm{H}, 6-$ $\left.\mathrm{NH}-\mathrm{COCH}_{3}\right), 3.40\left(\mathrm{~s}, 3 \mathrm{H}, 3-\mathrm{CH}_{3}\right), 4.13\left(\mathrm{~s}, 3 \mathrm{H}, 10-\mathrm{CH}_{3}\right)$, $8.03(\mathrm{~s}, 1 \mathrm{H}, 9-\mathrm{H})$.

Measurement of Oxidation-Reduction Potentials. These were determined by anaerobic titrations with dithionite of a solution of the particular flavin in the presence of a suitable dye in $0.1 \mathrm{M}$ potassium phosphate, $\mathrm{pH} 7.0$, at $22^{\circ} \mathrm{C}$, essentially as previously described (Edmondson \& Singer, 1973; Müller \& Massey, 1969). Indigo disulfonate $\left(E_{\mathrm{m}, 7}=-116\right.$ $\mathrm{mV}$; Clark, 1960) and safranin T $\left(E_{\mathrm{m}, 7}=-289 \mathrm{mV}\right.$; Clark, $1960)$ were the mediator dyes used in the titration of 6bromoriboflavin and of 6-amino flavins, respectively. Because of their low solubility at $\mathrm{pH} 7.0,6$-aminoriboflavin and 6amino-3-methyllumiflavin were first dissolved at high concentration $(\sim 7 \mathrm{mM})$ in $6 \mathrm{~N} \mathrm{HCl}$, followed by dilution into phosphate buffer and adjustment of the $\mathrm{pH}$ to 7.0. The maximal concentration of 6-amino-3-methyllumiflavin achieved even in this manner is $11 \mu \mathrm{M}$. The relative concentration of the oxidized and reduced forms of flavin was determined by the procedure of Moore et al. (1978), and the potential of the system was calculated from the Nernst equation after each addition of dithionite. The oxidationreduction potential was also determined coulometrically (Wilson, 1978) under anaerobic conditions, with $40-50 \mu \mathrm{M}$ flavin, $0.5 \mathrm{mM}$ methylviologen, and $0.5 \mathrm{mM} \mathrm{K}_{4} \mathrm{Fe}(\mathrm{CN})_{6}$ present, in order to avoid interference by the sulfite generated in dithionite titrations (Müller \& Massey, 1969).

EPR Spectra. Since the reduction of 6-S-cysteinyl flavins with $\mathrm{TiCl}_{3}$ in acid media produces flavin hydroquinones, not flavin cation radicals, the latter were generated by mixing equivalent amounts of oxidized and reduced flavins under Ar. The former was dissolved in $12 \mathrm{~N} \mathrm{HCl}$ and the latter, prepared by reduction with a stoichiometric amount of dithionite, was dissolved in $0.1 \mathrm{M}$ potassium phosphate, $\mathrm{pH}$ 7.2.

Other Methods. Absorption spectra were recorded with either a Cary 14 spectrophotometer interfaced with a Nova 2/4 computer (Data General Corp.) or a Cary 219, a Cary $118 \mathrm{C}$, or a Varian 635 Superscan spectrophotometer. Mass spectra were obtained with a Varian $\mathrm{CH}-7$ instrument. NMR spectra were obtained with a Varian EM-390 instrument at $35^{\circ} \mathrm{C}$ by using tetramethylsilane as the internal standard. Infrared spectra in $\mathrm{KBr}$ pellets were measured with a Perkin-Elmer 621 IR instrument. The photochemical experiments were carried out with the instrumentation described elsewhere
Scheme I

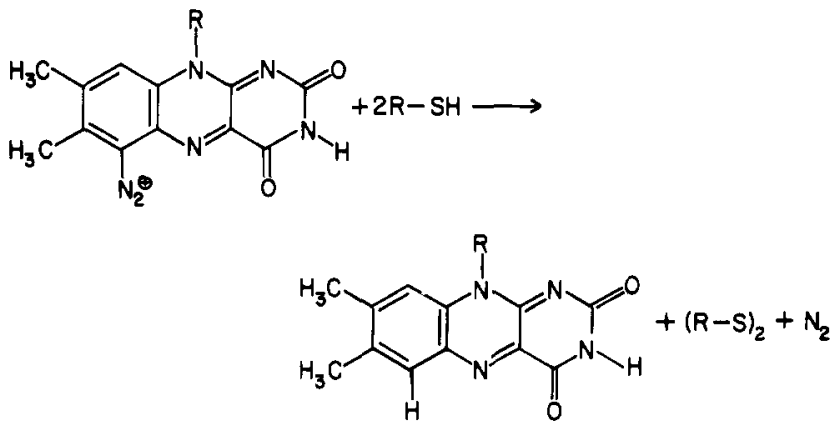

by Knappe (1975). EPR spectra were recorded with a Varian E-4 spectrometer.

\section{Results and Discussion}

Chemical Synthesis of 6-Substituted Flavins. In principle there are two approaches to the synthesis of flavins substituted in the 6 position. They may be prepared by condensing smaller ring systems, such as appropriately substituted $o$-phenylenediamines and alloxane [for a review, see Lambooy (1967)], or the desired group may be inserted into the intact isoalloxazine ring system (Berezovskii et al., 1972), the approach we have used in the present study. Since complications may occur during these syntheses, it seems appropriate to comment briefly on the procedures.

Although it has been reported that nitration of riboflavin or lumiflavin yields 9-nitroriboflavin or 6,9-dinitrolumiflavin, respectively (Berezovskii \& Aksel'rod, 1968; Litvak \& Berezovskii, 1978), more recently it has been established that the product believed to be 9-nitroriboflavin is the 6 isomer and that 6-nitrolumiflavin is the main product obtained on nitration of lumiflavin (Knappe, 1979). Moreover, the nitro group of these flavins can be reduced to the amino function either photochemically or with dithionite (Knappe, 1979). Such 6-amino flavins then become suitable starting compounds for the derivatization of the 6 position via the Sandmeyer reaction with (pseudo) halogens (Weygand \& Hilgetag, 1970). This reaction has been successfully applied to the synthesis of various 8-substituted flavins from the parent 8-amino flavins (Ghisla \& Mayhew, 1980). With the 6-amino flavins, the formation of the 6-diazotized compounds proceeded readily, but a high acid concentration $\left(5 \mathrm{M} \mathrm{H}_{2} \mathrm{SO}_{4}\right.$ ) was required to prevent the formation of unidentified dark decomposition products.

These diazonium salts are characterized by an orange color with absorption maxima at 462,343 , and $275 \mathrm{~nm}$ in $2 \mathrm{~N} \mathrm{HCl}$. The 6-diazonium flavins may be converted to the corresponding halide substituents under Sandmeyer conditions (Weygand \& Hilgetag, 1970). The order of reactivity observed was $\mathrm{I}^{-}>$ $\mathrm{Br}^{-}>\mathrm{Cl}^{-}$, the 6-chloro derivative being formed in 5-10\% yield.

Attempts to convert 6-diazonium flavins to 6-alkylthio or to 6-thio flavins by reaction with either alkylthiols or $\mathrm{HS}^{-}$, as had been successfully carried out with 8-diazotized flavins (Ghisla \& Mayhew, 1980), invariably failed. Although the expected products were formed in minor amounts, as shown by thin-layer chromatography, the major products obtained were the 6-unsubstituted flavins $[\mathrm{C}(6)-\mathrm{H}]$, which are probably formed via reductive elimination of the diazonium groups (Scheme I).

6-Iodo flavins were found to be essentially unreactive toward displacement with thiols in the $\mathrm{pH}$ range 9-11. The 6-bromo analogues, on the other hand, reacted albeit very slowly. For example, after $24-48 \mathrm{~h}$ of incubation under aerobic conditions at $\mathrm{pH} 9.5$ and $25^{\circ} \mathrm{C}$, over $90 \%$ of the 6-bromo flavin had 


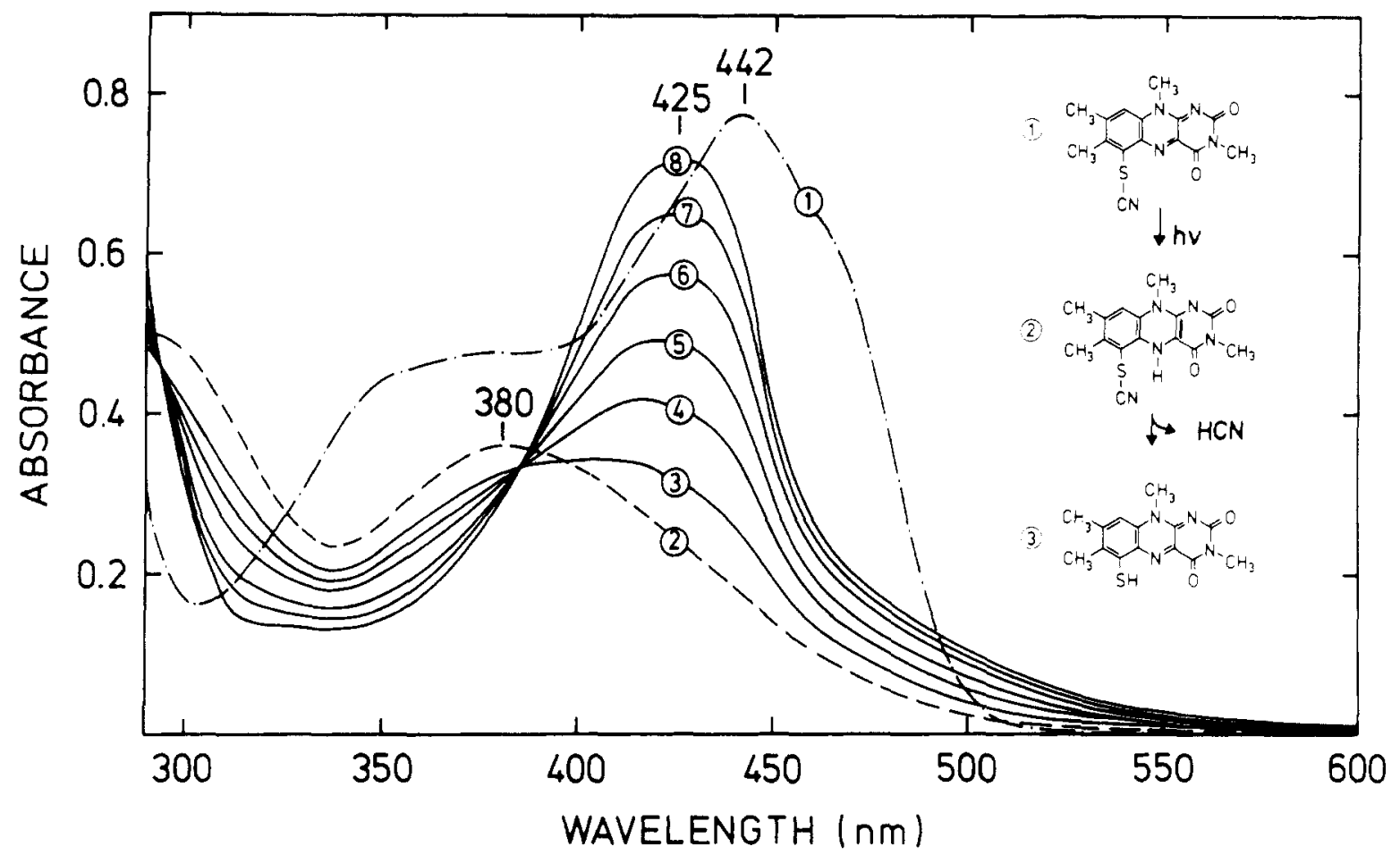

FIGURE 1: Spectral course of the intramolecular decomposition of 1,5-dihydro-6-(thiocyanato)-3-methyllumiflavin yielding 6-thio-3-methyllumiflavin and hydrogen cyanide. Curve 1: spectrum of 6-(thiocyanato)-3-methyllumiflavin, $6 \mu \mathrm{M}$, in $20 \%$ aqueous methanol containing 4 mM EDTA and $0.05 \mathrm{M}$ sodium sulfate, $\mathrm{pH} 2.5$. Curve 2: 1,5-dihydro-6-(thiocyanato)-3-methyllumiflavin obtained by illumination of 1 for $10 \mathrm{~s}$ with blue light $(420-480 \mathrm{~nm})$ under strictly anaerobic conditions. The following traces were obtained after $5,10,15,25,40$, and 80 min, respectively, of standing in the dark. Curve 8 represents the final product which is identical with 6-thio-3-methyllumiflavin.

Scheme II

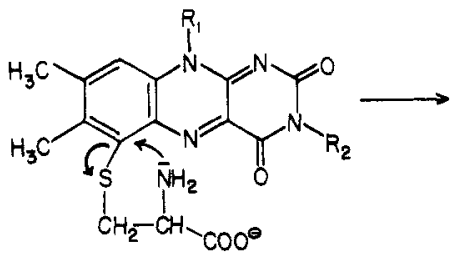<smiles>[R2]n1c(=O)nc2n([R2])c3cc(C)c(C)c(NC(C)=O)c3nc-2c1=O</smiles>

reacted in the presence of a 50 -fold molar exces of cysteine. The reaction must be carried out under aerobic conditions, since the rate of reduction of the flavin via the thiolate is comparable to the rate of substitution. Since reduced 6-bromo flavins are unreactive toward nucleophilic displacement with thiolates, the oxygen serves to reoxidize the flavin fraction reduced via the mercaptides. At higher $\mathrm{pH}$ values $(\mathrm{pH}>10)$, position $\mathrm{N}(3)$ of the flavin ionizes and this prevents nucleophilic attack at $\mathrm{C}(6)$. The $\mathrm{N}(3)$ position may be alkylated, as in 3-methyllumiflavin, but decomposition occurs at $\mathrm{pH}>11$ (Smith \& Bruice, 1975).

A further complication observed in this approach to the syntheses of 6-S-cysteinyl flavins was the formation of a rearrangement product, particularly at elevated temperatures. This can be separated from the desired product (6-S-cysteinyl flavin) on a column of Dowex 50 or DEAE-cellulose. The major contaminant has spectral properties very similar to those of 6-amino flavins (cf. Figure 3). This compound differs, however, from unsubstituted 6-amino flavin, as verified by thin-layer chromatography and its behavior on cation-exchange resins. This derivative is most probably a compound in which a Smiles $S \rightarrow N$ rearrangement (Truce et al., 1970) has occurred and in which the cysteinyl moiety still remains attached to the flavin (Scheme II). A similar rearrangement has been observed with 8-S-cysteinyl flavins. Indeed, the reaction is sufficiently fast in this case that the amino group of the cysteine must be protected by acylation during synthesis
(Moore et al., 1979; S. Ghisla, V. Massey, and P. Hemmerich, unpublished experiments).

A thio group can also be introduced into the 6 position by incubation of the 6-diazonium flavin with thiocyanate or ethylxanthate. For preparative purposes this is the preferred method. The 6-thiocyanate and 6-ethylxanthate derivatives of 3-methyllumiflavin were obtained in crystalline form and in good yield. These reactions proceed equally well with the riboflavin analogues, although the products failed to crystallize readily. The conversion of these compounds to the 6-SH compound by classical methods (Weygand \& Hilgetag, 1970) is feasible, but a much simpler procedure was developed, based on the peculiar reactivity of 6-thiosulfato flavin, which eliminates sulfite upon reduction (Steenkamp et al., 1978b). Thus, reduction of 6-thiocyanato flavins at $\mathrm{pH}>4$ yields immediately the green color of 6-thio flavin anion. That this reaction proceeds through formation of a reduced flavin intermediate is shown in Figure 1. When 6-(thiocyanato)-3-methyllumiflavin was reduced with EDTA and light (Massey et al., 1978) under anaerobic conditions, a species rapidly formed which had the characteristic absorption spectrum of reduced flavins carrying electron-withdrawing substituents and which have the 1,5-dihydro flavin structure (Knappe, 1980). An isosbestic reaction with a first-order rate constant of 0.046 $\mathrm{min}^{-1}$ then follows, leading to the formation of 6-thio-3methyllumiflavin (Figure 1). 6-Thio-FMN, derived from the covalently bound flavin component of trimethylamine dehydogenase, is known to react rapidly with oxygen to form the dimeric flavin disulfide (Steenkamp et al., 1978b). Analogous behavior has been observed with synthetic 6-thio flavins in the present study, As shown in Figure 2, the oxidation of 6thio-3-methyllumiflavin by oxygen proceeds isosbestically to form the sulfide dimer. This species can be reconverted to the monomeric anion by reduction with dithionite, sodium borohydride, or EDTA and light. 


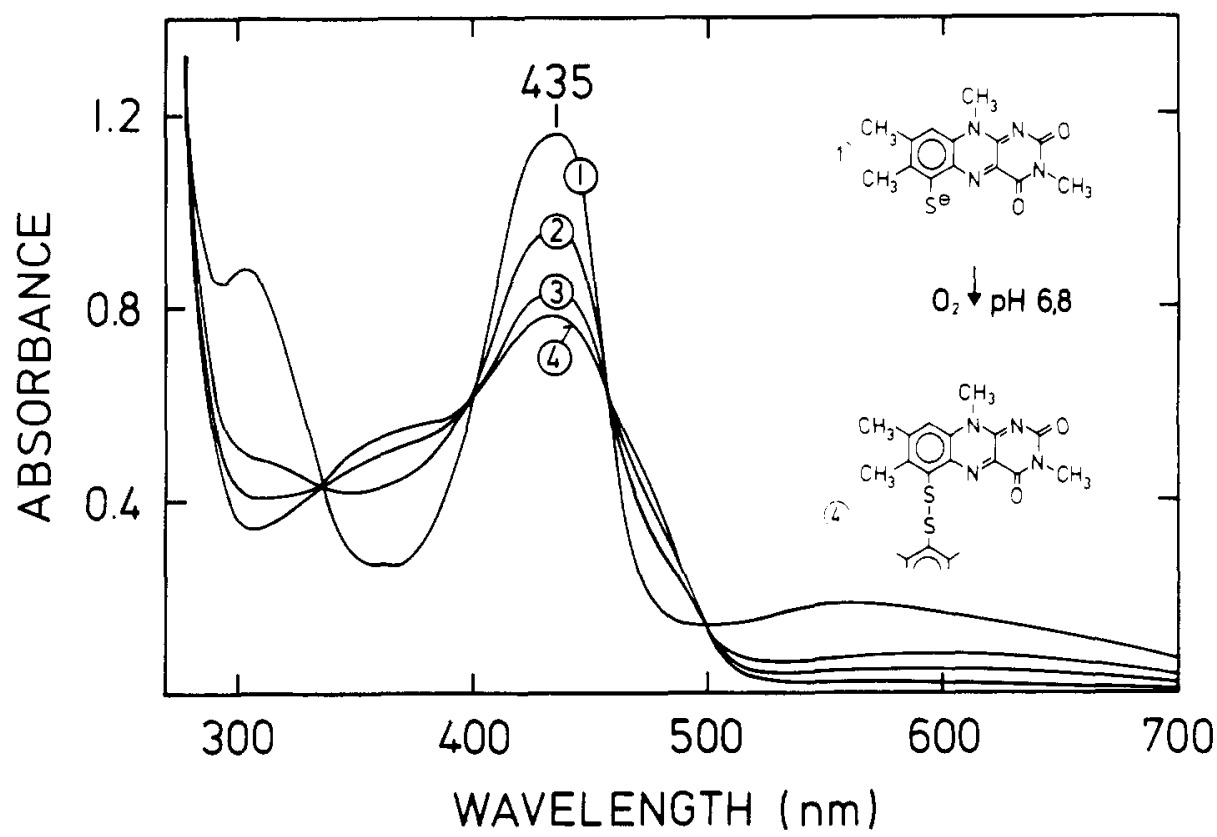

FIGURE 2: Spectral course of the oxidation of 6-thio-3-methyllumiflavin (anion) by air, yielding the corresponding disulfide. Curve 1: 6-thio-3-methyllumiflavin anion in $20 \%$ aqueous methanol, $0.05 \mathrm{M}$ in sodium phosphate, $\mathrm{pH} 6.8$, was formed in situ via photoreduction of 6-(thiocyanato)-3-methyllumiflavin in the presence of EDTA (cf. legend of Figure 1). Upon admission of air, spectra 2, 3, and 4 were recorded after 5,15 , and $30 \mathrm{~min}$. Note the disappearance of the long-wavelength absorbance at $560 \mathrm{~nm}$. Curve 4 represents the spectrum of 6,6'-bis(3-methyllumiflavin) disulfide.

Qualitatively, the reactivity of 6-bromo, 6-iodo, and 6-diazonium flavins toward nucleophilic displacement is similar to that of the vinyl analogue 8-substituted flavins. However, while the latter shows a reactivity which is comparable to that of dinitrobenzene derivatives (Moore et al., 1979), with 6substituted flavins this reactivity is lowered by several orders of magnitude. Worth noting also is the rapid oxidation of 6-thio flavins to the corresponding disulfide by oxygen, as compared to 8-thio flavins (Moore et al., 1979). These properties probably reflect the difference in electron density at the 6 and 8 positions, respectively, a feature which is also shown by the differences in $\mathrm{p} K_{\mathrm{a}}$ values of 6-hydroxy $\left[\mathrm{p} K_{\mathrm{a}}=\right.$ 7.1 (Mayhew et al., 1974)] and 8-hydroxy [p $K_{\mathrm{a}}=4.8$ (Ghisla \& Mayhew, 1976)] flavins.

Spectral Properties of 6-Amino Flavins. Flavin coenzymes carrying a nitrogen substituent in the $\mathrm{C}(6)$ position of the isoalloxazine ring system have not as yet been described as occurring in nature. In view of the number of different types of modification which have been uncovered so far (Edmondson \& Singer, 1976; Kenney, 1980), it seems probable that 6amino flavins might also occur as natural cofactors. One possibility is covalent linkage of the flavin via the $\epsilon$-amino group of a lysyl residue in a protein. The spectral properties of 6-amino flavins, the putative parent compound of such coenzymes, are, therefore, of potential interest and were investigated in some detail. The 6-amino flavin chromophore is characterized by relatively small absorbance changes with $\mathrm{pH}$ at wavelengths greater than $500 \mathrm{~nm}$ and by a single, relatively narrow band in the 390-430-nm region, the position of which is $\mathrm{pH}$ dependent (Figure 3). Their spectral properties are similar to those of 6-hydroxy flavin anions (Mayhew et al., 1974; Schöllnhammer \& Hemmerich, 1974) and to 6-keto flavins, in which an "orthoquinoid structure" is obtained by alkylation at the $\mathbf{N}(1)$ position of the flavin (Schöllnhammer $\&$ Hemmerich, 1974). By analogy, it appears that the neutral and the monoanionic forms of 6-amino flavins, which have very similar spectra, should have the orthoquinoid structure shown in Figure 3. Consequently, the deprotonation step with a $\mathrm{p} K_{\mathrm{a}}$ $\cong 10.3$ would be expected to occur at $\mathrm{N}(1)-\mathrm{H}$. That the

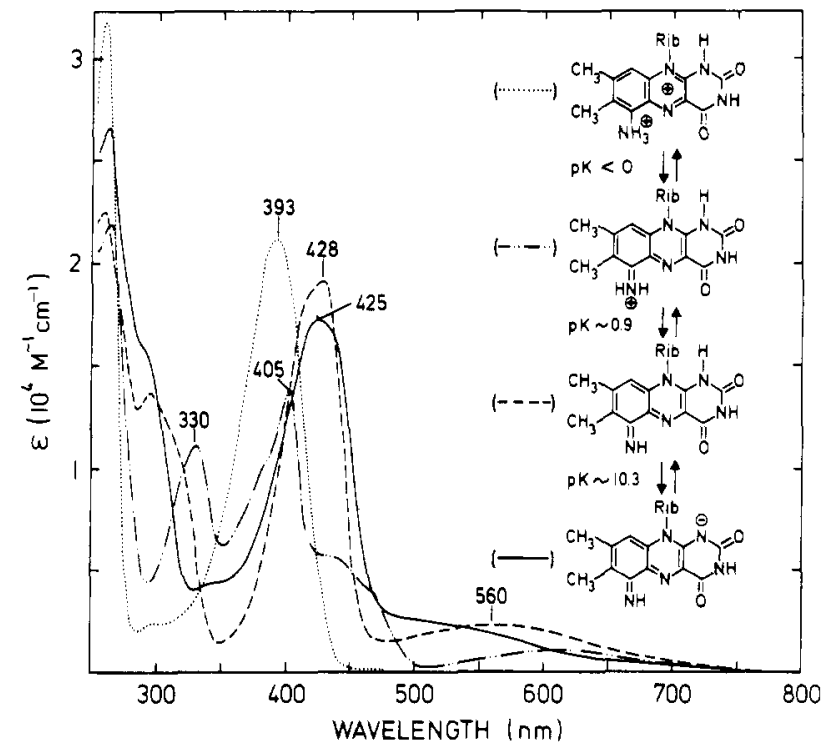

FIGURE 3: Absorption spectra of 6-aminoriboflavin as function of the ionization state. Curve $\cdots$, in $70 \% \mathrm{HClO}_{4}$; curve -..., in $2 \mathrm{~N} \mathrm{HCl}$; curve $\ldots$, in $0.1 \mathrm{M}$ sodium phosphate, $\mathrm{pH} 7.0$; curve - , in $0.01 \mathrm{~N} \mathrm{NaOH}$ solution.

neutral orthoquinoid form shown in Figure 3 is present in the $\mathrm{pH}$ range 2-8, and not the possible mesoionic structure [carrying a positive charge on the 6-amino function and a negative one on the $\mathrm{N}(1)-\mathrm{C}(2)=0$ function], is indicated by the lack of solvatochromy, when the spectra are recorded in solvents of different polarity (water to benzene). The protonation with a $\mathrm{p} K_{\mathrm{a}}$ of 0.9 occurs predominantly at the 6-amino function (Figure 3 ), but the complexity of the spectrum indicates that other tautomers possibly exist as well. In strong acid, the dicationic form must be present, as shown by the single absorption band at $393 \mathrm{~nm}$, which is characteristic of isoalloxazines carrying a positive charge on the nucleus and in which an exocyclic conjugation is absent (Dudley et al., 1964).

Acylation of the amino group of 6-amino flavins gives rise 


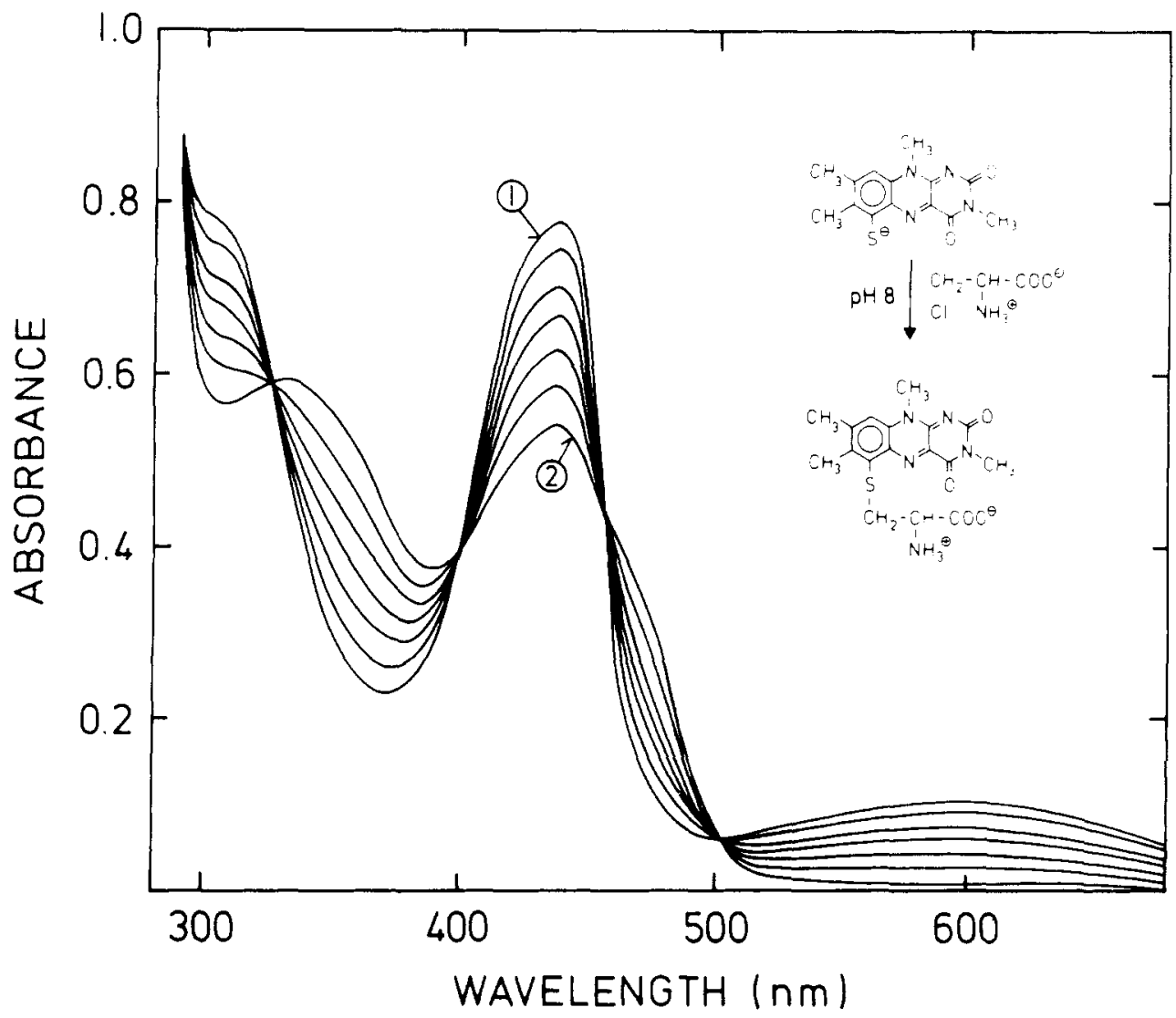

FIGURE 4: Spectral course of the alkylation of 6-thjo-3-methyllumiflavin anion with $\beta$-chloroalanine $(0.4 \mathrm{M})$ at $\mathrm{pH} 8$ and $25^{\circ} \mathrm{C}$. Curve 1 : spectrum of 6-thio-3-methyllumiflavin anion produced in situ by photoreduction of 6-(thiocyanato)-3-methyllumiflavin (cf. Figure 1). The following curves, which are corrected for dilution, were recorded after anaerobic addition of $\beta$-chloroalanine at $3,5,7,10,14$, and $30 \mathrm{~h}$. Curve 2 represents the spectrum of 6-S-cysteinyl-3-methyllumiflavin. Note the decrease of the long-wavelength absorbance at $600 \mathrm{~nm}$ and the formation of a new second absorbance band at $340 \mathrm{~nm}$.

to a typical flavin-type absorption spectrum with maxima at 450 and $350 \mathrm{~nm}$. In this compound, conjugation of the nitrogen with the aromatic ring system is blocked. Similar effects have been obtained upon oxidation of the sulfur moieties in 6-thio flavins (Steenkamp et al., 1978a) and in 8-thio flavins (Moore et al., 1979), as well as acetylation of 6-hydroxy and 8-hydroxy flavins (Schöllnhammer \& Hemmerich, 1974; Ghisla \& Mayhew, 1976).

Identity of Native and Synthetic 6-S-Cysteinyl Flavins. Alkylation of synthetic 6-thio flavin anion with an excess of $\beta$-chloroalanine yields a compound with spectral properties indistinguishable from those of the aminoacyl coenzyme of trimethylamine dehydrogenase (Steenkamp et al., 1978a,b) (Figure 4). The properties of this synthetic compound (6$S$-cysteinylriboflavin) are identical with those of the dephosphorylated form of the aminoacyl coenzyme of trimethylamine dehydrogenase in every respect examined. Both compounds are converted to the thiolate on illumination at $\mathrm{pH} \mathrm{8.0.} \mathrm{This}$ is accompanied by absorbance changes which are just the reverse of those in Figure 4. Synthetic 6-S-cysteinylriboflavin and the natural compound (Steenkamp et al,, 1978a) are both converted by peroxy acids to the same chromophore. The synthetic and natural compounds show the same absorption spectra in $6 \mathrm{~N} \mathrm{HCl}$, at neutral $\mathrm{pH}$, and in $0.1 \mathrm{~N} \mathrm{NaOH}$, indicating the presence of the same ionizing groups. Their mobilities at the riboflavin level $(-0.6$, as compared to mobility of FMN $=1.0$ ) are identical in high-voltage electrophoresis at $\mathrm{pH} 1.9[5 \%(\mathrm{v} / \mathrm{v})$ formic acid] and on silica gel thin-layer chromatography $\left(R_{f} \simeq 0.36\right.$ in 1-butanol-acetic acid-water, 4:3:2 v/v/v). Further, illumination of the spots following such chromatographic separation at $\mathrm{pH} 2.5$ results in the formation

\begin{tabular}{lccc}
\hline Table I: & Oxidation-Reduction Potentials of 6-Substituted Flavins \\
\hline \multicolumn{1}{c}{ flavin } & $\begin{array}{c}\text { method } \\
\text { of red }{ }^{\alpha}\end{array}$ & $E_{0}{ }^{\prime}(\mathrm{mV})$ & $\begin{array}{c}n \\
\text { value }\end{array}$ \\
\hline riboflavin & $\mathrm{C}$ & -199 & 2.1 \\
6-bromoriboflavin & $\mathrm{C}$ & -144 & 2.1 \\
6-bromoriboflavin & $\mathrm{D}$ & -149 & 2.4 \\
6-aminoriboflavin & $\mathrm{D}$ & -293 & 1.7 \\
6-amino-3-methyllumiflavin & $\mathrm{D}$ & -320 & 2.0 \\
6-( $N$-acetylamino)-3- & $\mathrm{C}$ & -185 & 2.0 \\
methyllumiflavin & \multicolumn{4}{c}{-154} & 2.0 \\
6- $S$-cy steinyl-FMN & $\mathrm{C}$ & -154 \\
\hline${ }^{a} \mathrm{C}$ is coulometric titration; D is dithionite reduction in the \\
presence of dyes.
\end{tabular}

of a product with a whitish blue fluorescence $\left(\lambda_{\max } \simeq 500 \mathrm{~nm}\right)$, a property previously noted with the naturally occurring compound when illumination was performed at acid $\mathrm{pH}$ values (Steenkamp \& Singer, 1976).

These data confirm, beyond doubt, that the coenzyme of trimethylamine dehydrogenase is the monophosphate of 6-Scysteinyl-7,8-dimethyl-10-D-ribitylisoalloxazine, as was previously postulated (Steenkamp et al., 1978a,b).

Oxidation-Reduction Potentials of 6-Substituted Flavins. The results of the determination of the oxidation-reduction potentials of 6-substituted flavins are summarized in Table I. From the data presented, the profound influence of 6 substitution on the oxidation-reduction potential of the flavin is apparent. Whereas 6-bromoriboflavin has a redox potential of $-144 \mathrm{mV}$ at $\mathrm{pH} \mathrm{7,6-aminoriboflavin} \mathrm{has} \mathrm{a} \mathrm{potential} \mathrm{of}-293$ $\mathrm{mV}$. These may be compared with a value of $-199 \mathrm{mV}$ for the parent compound, riboflavin. 
Scheme III

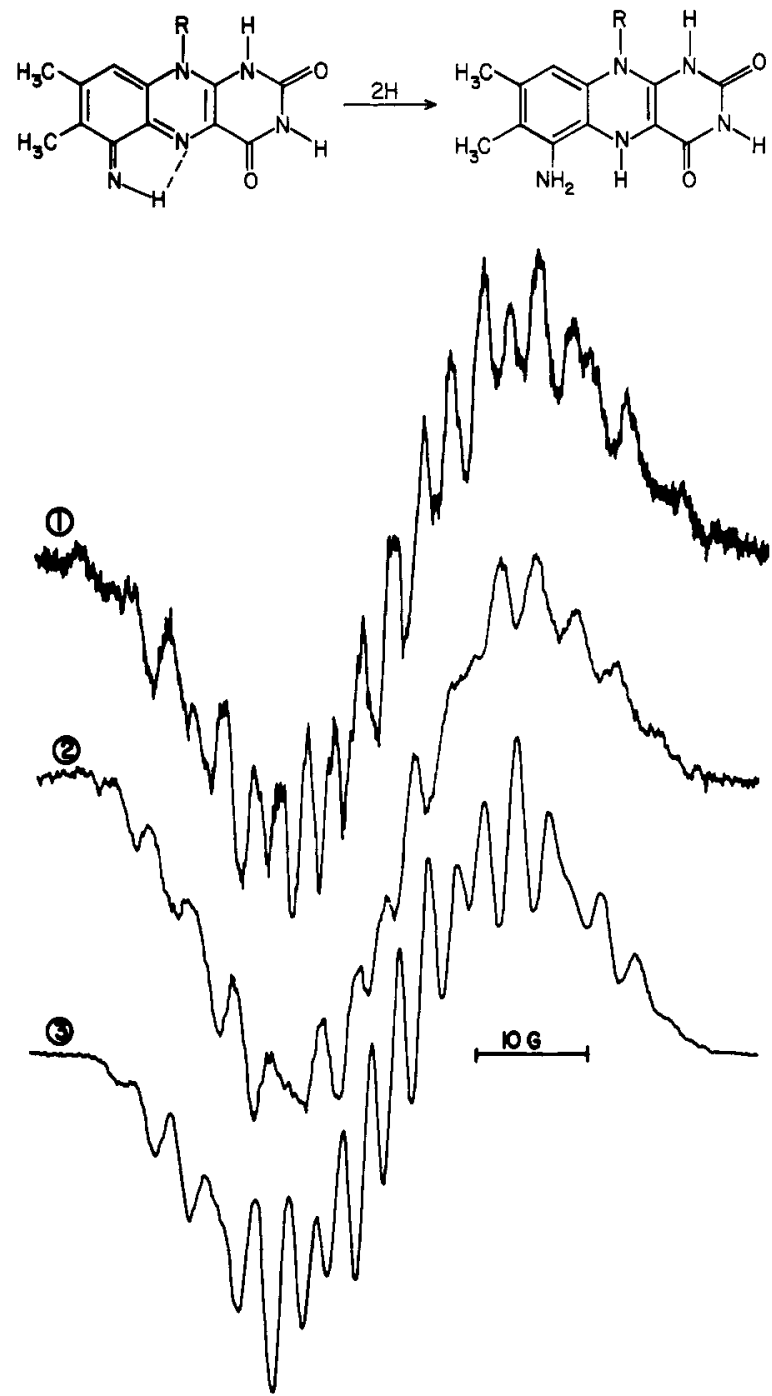

FIGURE 5: EPR spectra of cationic semiquinone forms of 6-S-cysteinyl flavins. Flavin concentrations were $3-4 \mathrm{mM}$ in $6 \mathrm{~N} \mathrm{HCl}$. Upper: 6-S-cysteinyl-3-methyllumiflavin (microwave frequency, $9.062 \mathrm{GHz}$; microwave power, $3.5 \mathrm{~mW}$; modulation frequency, $100 \mathrm{kHz}$; modulation amplitude, $0.8 \mathrm{G}$ ). Middle: $6-S$-cysteinyl-FMN from trimethylamine dehydrogenase (microwave power, $1.0 \mathrm{~mW}$; modulation amplitude, $1.6 \mathrm{G}$ ). Lower: 6-bromoriboflavin (microwave power, $2 \mathrm{~mW}$; modulation amplitude, $1.0 \mathrm{G}$ ).

The reason for the unexpected behavior of 6-amino flavins may be due to the formal reduction of the $\mathrm{N}(5)-\mathrm{C}(6)-\mathrm{N}$ system rather than to the "usual" reduction of the $\mathrm{N}(1)-\mathrm{N}(5)$ system of other flavins (Scheme III). When the amino group is acetylated, the potential is reconverted to nearly that of normal flavin.

The oxidation-reduction potential of 6-S-cysteinyl-FMN, the covalently bound cofactor of trimethylamine dehydrogenase, is $-154 \mathrm{mV}$, considerably more positive than that of FMN (-216 mV; Clark, 1960). Estimation of the oxidation-reduction potential of this aminoacyl coenzyme via flavin-sulfite complex formation according to the procedure of Müller \& Massey (1969) gave comparable results.

It may be mentioned that the potentials obtained by the two procedures in Table I were always in good agreement. Examples of this are the values for 6-bromoriboflavin (Table I). The coulometric procedure is particularly useful when no indicator dyes are available with suitable potential and spectral properties as is the case for the naturally occurring $6-S$-cysteinyl-FMN.
EPR Spectra of 6-S-Cysteinyl Flavins. Figure 5 shows the EPR spectra of the cation radicals of 6-S-cysteinyl-3methyllumiflavin, 6-S-cysteinyl-FMN isolated from trimethylamine dehydrogenase, and 6-bromoriboflavin. The first of these has a line width of $60 \mathrm{G}$ with 20 to 21 peaks and a $g$ value of 2.0070; the second compound has a line width of $57 \mathrm{G}$ with 16 to 17 peaks and a $g$ value of 2.0073 ; the third one has a $57-\mathrm{G}$ line width, 18 peaks, and a $g$ value of 2.0085 . The difference in the line width and the number of peaks is due to the different substituents at the $C(6)$ and $N(10)$ positions of these three compounds. The total width is comparable to that of the parent flavin in accordance with the rather small effect expected from the removing of the small coupling constant of the 6-H. A sulfur or bromine should not give major hyperfine couplings. These results may be contrasted with those obtained for $8 \alpha$-substituted flavins in which the total width of the spectrum is reduced relative to that of the parent compound (Salach et al., 1972).

\section{Acknowledgments}

S.G. acknowledges many discussions with Professor P. Hemmerich and his interest in this work.

\section{References}

Berezovskii, V. M., \& Aksel'rod, Zh. I. (1968) Dokl. Akad. Nauk SSSR 180, 607-610.

Berezovskii, V. M., Tul'chinskaya, L. S., \& Polyakova, N. A. (1972) Russ. Chem. Rev. (Engl. Transl.) 41, 574-591. Blankenhorn, G., Osuga, D. T., Lee, H. S., \& Feeney, R. E. (1975) Biochim. Biophys. Acta 386, 470-478.

Clark, W. M. (1960) Oxidation-Reduction Potentials of Organic Systems, Williams and Wilkins, Baltimore, MD.

Dudley, K. H., Ehrenberg, A., Hemmerich, P., \& Müller, F. (1964) Helv. Chim. Acta 47, 1354-1383.

Edmondson, D. E., \& Singer, T. P. (1973) J. Biol. Chem. 248, 8144-8149.

Edmondson, D. E., \& Singer, T. P. (1976) FEBS Lett. 42, 1-14.

Ghisla, S., \& Mayhew, S. G. (1976) Eur. J. Biochem. 63, 373-390.

Ghisla, S., \& Mayhew, S. G. (1980) Methods Enzymol. (in press).

Kenney, W. C. (1980) Flavins Flavoproteins, Proc. Int. Symp., 6 th, 237-243.

Knappe, W. R. (1975) Chem. Ber. 108, 2422-2438.

Knappe, W. R. (1979) Justus Liebigs Ann. Chem. 1979, 1062-1080.

Knappe, W. R. (1980) Flavins Flavoproteins, Proc. Int. Symp., 6th, 469-474.

Lambooy, J. P. (1967) Heterocycl. Compd. 9, 118-223.

Litvak, Zh. I., \& Berezovskii, V. M. (1978) Zh. Org. Khim. $14,440-446$.

Massey, V., Stankovich, M., \& Hemmerich, P. (1978) Biochemistry 17, 1-8 and references cited therein.

Mayhew, S. G., \& Strating, M. J. (1975) Eur. J. Biochem. 59, 539-544.

Mayhew, S. G., Whitfield, C. D., Ghisla, S., \& SchumanJorns, M. (1974) Eur. J. Biochem. 44, 579-591.

Moore, E. G., Cardemil, E., \& Massey, V. (1978) J. Biol. Chem. 253, 6413-6422.

Moore, E. G., Ghisla, S., \& Massey, V. (1979) J. Biol. Chem. 254, 8173-8178.

Müller, F., \& Massey, V. (1969) J. Biol. Chem. 244, 4007-4016. 
Salach, J., Walker, W. H., Singer, T. P., Ehrenberg, A., Hemmerich, P., Ghisla, S., \& Hartmann, U. (1972) Eur. J. Biochem. 26, 267-278.

Schöllnhammer, G., \& Hemmerich, P. (1974) Eur. J. Biochem. 44, 561-577.

Smith, S. H., \& Bruice, T. C. (1975) J. Am. Chem. Soc. 97, 2875-2881.

Steenkamp, D. J., \& Mallinson, J. (1976) Biochim. Biophys. Acta 429, 705-719.

Steenkamp, D. J., \& Singer, T. P. (1976) Biochem. Biophys.
Res. Commun. 71, 1289-1295.

Steenkamp, D. J., Kenney, W. C., \& Singer, T. P. (1978a) J. Biol. Chem. 253, 2812-2817.

Steenkamp, D. J., McIntire, W., \& Kenney, W. C. (1978b) J. Biol. Chem. 253, 2818-2824.

Truce, W. E., Kreider, E. M., \& Brand, W. W. (1970) Org. React. (N.Y.) 18, 99-215.

Weygand, K., \& Hilgetag, G. (1970) Organisch-chemische Experimentier-kunst, 4th ed., p 675, Barth, Leipzig. Wilson, G. S. (1978) Methods Enzymol. 54, 396-410. 